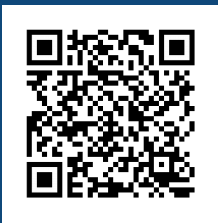

Keywords:

Seating torque

Stripping torque

Torque transducer

Minor and major diameter of screw

Historic: Received 23/10/2018 Accepted 04/02/2019

Correspondence: ondertor@kastamonu.edu.tr
Onder Tor ${ }^{1 a}$

\section{EFFECTS OF PILOT HOLE DIAMETER ON SCREW-DRIVING TORQUES IN MEDIUM DENSITY FIBERBOARD}

TOR, O. Effects of Pilot Hole Diameter on Screw-Driving Torques in Medium Density Fiberboard. CERNE, v. 25, n. I, p. 54-59, 2019.

\section{HIGHLIGHTS}

The pilot-hole diameter needs to be chosen carefully driving screws into MDF.

Too much torque applied in the MDF will cause stripping problem.

The large pilot-hole diameter such as $3.2 \mathrm{~mm}$ needs to be preferred than the narrower ones in edge of MDF in order not to cause splitting.

\section{ABSTRACT}

This study investigated the effects of pilot-hole diameter in medium density fiberboard (MDF) on the characterization of screw-driving torques. The factors investigated were the embedded screw orientation and pilot hole diameter. Based on the curves obtained from screw-driving process, the measurements of the seating torque (SET) and stripping torque (STT) were obtained. The results of statistical analysis indicated that the SET and STT values in MDF were significantly affected by the pilot hole diameter. In the case of driving screws into the side of MDF material, the mean SET ranged from 0.37 to 1.23 $\mathrm{N} \cdot \mathrm{m}$ and STT values ranged from I.I8 to $2.68 \mathrm{~N} \cdot \mathrm{m}$ whereas for the face specimens, the mean SET ranged from 0.57 to $\mathrm{I} .56 \mathrm{~N} \cdot \mathrm{m}$ and STT values ranged from 2.89 to $5.4 \mathrm{I} \mathrm{N} \cdot \mathrm{m}$. 


\section{INTRODUCTION}

Seating problems in screws arise when screws are insufficiently tightened into a material due to lack of sufficient value of torque. Meanwhile, the application of excessive torque to a screw may lead to stripping issues. Additionally, over-torque can also damage the host material if the fastener fails due to overstressing. The torque requirements for particular applications should be determined and then the appropriate torque should be applied to induce the clamping force essential for the realization of a reliable screw-fastened assembly (Tor et al, 2016). To this end, it is important to determine the minimum and maximum screw-driving torques in materials such as the wood-based composites that are used for structural and nonstructural applications. Since medium density fiberboard (MDF) was one of the most commonly used wood-based composites used extensively for furniture, shelving, cabinetry and molding (Cai, 2006), it was selected in the proposed study. Therefore, knowledge of screw performance based on the screw-driving torque required for assemblies made with MDF is important for its correct use.

The screw-driving process was divided into three stages. (Boulanger, 2009; Tor et al, 2015; Robert, 2015) The first was the thread-forming stage, where the torque was increased steadily as the screw forms threads without cutting the material, ultimately reaching the maximum drive torque (MDT) and seating torque (SET). MDT was the value of torque at the first turning point at which clamping started. Second was the clamping stage, in which the screw started the tightening process, compressing the component parts and ultimately reaching the STT. In the final stage called the screw-stripping stage, the torque value dropped dramatically as the torque passes STT. Researches based on wood-based composites are limited to oriented strandboard (OSB), particleboard (PB), and wood plastic composites (WPC) (Tor et al, 20I5; Yu et al, 2015 and Kuang, 20I7). The characteristics associated with driving screws into six different types of particleboard (PB) were examined. The results indicated that the mean SET values for driving a screw into the face of a PB material ranged from 0.9 to $1.92 \mathrm{~N} \cdot \mathrm{m}$, while the mean stripping torque ranged from 3.73 to $6.55 \mathrm{~N} \cdot \mathrm{m}$. The mean STT to SET ratio ranged from 2.5 to 5.0. The seating and stripping torques in PB materials with pilot holes were found to be lower than in the case with no pilot-holes (Yu et al., 20I5). There is no such information about the screw-driving torques in MDF.

The screw holding strength in the face and edge orientations in MDF and PB were studied by Ithnin et al. (1993). They reported that the use of pilot holes with an appropriate diameter significantly increased the screw holding strength in the material, concluding that, in general, the diameter of a pilot hole should be at least $85 \%$ of the minor diameter of the screw and no larger than $90 \%$. In addition, they stated that internal bond (IB) test was another factor which affected the edge-splitting tendency of MDF, particleboard, and spruce plywood. It was found that the edge-splitting tendency decreased as the pilot-hole diameter was increased from $60 \%$ to $85 \%$ of the outer diameter of the screw threads and resulted in decrease in the edge withdrawal resistance. The edgesplitting tendency of fiberboard was considerably greater than that of particleboard or plywood. Lateral loading of screws in furniture or cabinet joints could increase the edge-splitting tendency (Didriksson et al., 2003). Determining the relation between driving torques and their effect would help manufacturers to reduce some quality issues, notably substandard connection strength caused by stripped screws in MDF and reduce health issues related.

Therefore, the primary objective of the proposed study was to acquire basic information about the characteristic torques required for driving screws into MDF. The specific objectives were as follows: I) To obtain average values of screw-driving torques from the recorded torque-time curves; 2) To investigate the effects of embedded screw orientation and pilot-hole diameter on screw-driving torques and 3) To propose a regression technique to derive an empirical equation for prediction of screw-driving torques considering significant factors in MDF.

\section{MATERIAL AND METHODS}

The methodology of the present study is as follows:

Materials

Full-sized MDF panels $(2460 \mathrm{~mm}(\mathrm{~L}) \times 1250$ $\mathrm{mm}(\mathrm{W}) \times 18.26 \mathrm{~mm}(\mathrm{~T}))$ were provided by Lowe's Companies Inc. in Starkville, Mississippi. No. I0-gage, 38.I-mm long flathead, and zinc plated Philips low carbon steel wood screws were chosen for this study. The minor and major diameters of the screws were 3.4 and $4.7 \mathrm{~mm}$, respectively. A metal plate, $19 \mathrm{~mm}$ thick, was used to ensure the consistency of the pilot hole depths in the torque-testing blocks as shown in Figure I.

\section{Experimental Design}

A complete two-factorial experiment with 20 replications per combination was conducted to evaluate the effects of the relevant factors on the SET and STT when driving screws into MDF. The two factors were 
pilot hole diameter $(0,2.8,3.2,3.6,4.0$, and $4.4 \mathrm{~mm})$ and embedded screw orientation (side and face). Table I shows the percentage of minor ad major diameter of screw over pilot hole diameters. Therefore, a total of 240 screw-driving tests were performed on 240 specimen blocks. A total of 480 values were obtained for two different screw-driving torques. Each testing block had dimensions of $152.4 \mathrm{~mm}(\mathrm{~L}) \times 76.2 \mathrm{~mm}(\mathrm{~W})$ $\times 18.26 \mathrm{~mm}(T)$ (ASTM D I037-06, 2010).

TABLE I Pilot hole diameter, percentage of minor and major diameters of screw.

\begin{tabular}{ccc}
\hline \multirow{2}{*}{$\begin{array}{c}\text { Pilot hole diameter } \\
(\mathrm{mm})\end{array}$} & \multicolumn{2}{c}{$\begin{array}{c}\text { Percentage } \\
(\%)\end{array}$} \\
\cline { 2 - 3 } & $\begin{array}{c}\text { Major diameter (4.7 } \\
\mathrm{mm})\end{array}$ & $\begin{array}{c}\text { Minor diameter }(3.4 \\
\mathrm{mm})\end{array}$ \\
\hline 2.8 & 60 & 81 \\
3.2 & 68 & 93 \\
3.6 & 77 & 104 \\
4.0 & 85 & 116 \\
4.4 & 94 & 127 \\
\hline
\end{tabular}

Specimen Preparation and Torque Measurement

All the torque-testing blocks were cut from the full-size 18.26-mm MDF panels (I.25 × $2.46 \mathrm{~m})$, and then conditioned in an equilibrium moisture content chamber set to $20 \pm 3^{\circ} \mathrm{C}$ and $65 \pm 5 \%$ relative humidity for two weeks. Pilot holes with 12.7 and $19 \mathrm{~mm}$ deep were drilled in the center of the face and side testing blocks, such that the total depth of the hole was 31.7 and $38 \mathrm{~mm}$, respectively when the testing block was combined with the metal plate. All the torque measurements were taken immediately after the pilot holes had been drilled into the testing blocks. The physical and mechanical properties were evaluated in accordance with the procedures described in ASTMD444292 (20I0) and ASTM D I037-06 (2010), respectively. The test setup for obtaining the torque data when the screws were driven into the side of the testing blocks as shown in Figure I. The torque measurement apparatus consisted of a TT500FH dial screwdriver attached to an RTSX 100i rotary transducer (Mountz, Foley, AL) and a laptop on which Mountz torque \& force analyzer was installed. This used a CFIl card and ran the Wizard Plus software (Mountz, San Jose, CA). The operating range of the torque transducer was I.13-II.3 N.m for which the collecting rate was 50 points/sec.. The screw-driving process ended between $2-4$ sec. after the material stripped.

\section{Statistical Analyses}

A general linear model (GLM) procedure using the full linear model below [I] for a two-factor analysis of variance (ANOVA) was performed to analyze significance of two main effects and their interactions on the means of the SET and STT of the MDF specimens. Where:

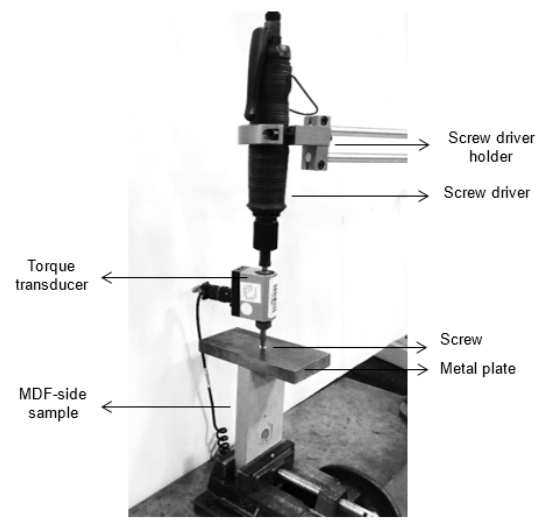

FIGURE I Test setup for obtaining the torque data for side specimen of MDF.

$T_{p s}=$ screw-driving torque (N.m); SET and STT; $\mu$ =overall mean of screw-driving torque $(\mathrm{N} \cdot \mathrm{m}) ; \quad \alpha_{p}=$ continuous variable reprensenting effect of pilot hole diameter $(\mathrm{mm})$, $p=0,2.8,3.2,3.6,4.0$, and $4.4 ; \beta_{s}=$ discrete variable representing effect of embedded screw orientation $(\mathrm{N} \cdot \mathrm{m})$, $s=$ face and side; $\quad \varepsilon_{f t b s m}=$ random term, $\mathrm{m}=20$ replicate; rest terms are two-factor interactions

$\mathrm{T}_{p s}=\mu+\alpha_{p}+\beta_{s}+(\alpha \beta)_{p s}+\varepsilon_{p s}$

The protected least significant difference (LSD) multiple comparison procedure was also performed, followed by ANOVA to compare the means and whether there was any significant interaction between the factors. Otherwise, the main effects were observed. All the statistical analyses were performed at a $5 \%$ significance level.

\section{RESULTS AND DISCUSSION}

Table 2 summarizes the mean values of some physical and mechanical properties, such as the measured density, moisture content (MC), and internal bond (IB) strength for the MDF specimens, evaluated in the proposed study.

TABLE 2 Physical and mechanical properties of MDF specimens.

\begin{tabular}{ccccc}
\hline \multicolumn{4}{c}{ Density $\left(\mathrm{g} \cdot \mathrm{cm}^{-3}\right)$} \\
\hline Overall & Core & Surface & $\mathrm{MC}(\%)$ & IB (MPa) \\
$0.62(9) *$ & $0.48(4)$ & $0.84(5)$ & $8.1(3)$ & $0.76(4)$ \\
\hline
\end{tabular}

* Values in parentheses are coefficient of variation (\%).

Torque-time curve

Figure 2 shows a typical torque-time curve recorded when screws were being driven into the MDF specimens. This screw-driving process were divided into three stages, namely, the thread-forming stage, where the torque was increased at an increasing rate as the screw formed threads without cutting the material, ultimately 
reaching the MDT and SET. Immediately after this stage was the clamping stage, where the screw started the tightening process, compressing the metal plate against the testing block and ultimately reaching the STT. In the final stage, called the screw-stripping stage, the torque dropped dramatically once STT was exceeded. There were no data points in this stage (Boulanger, 2009 and Tor et al, 20I5).

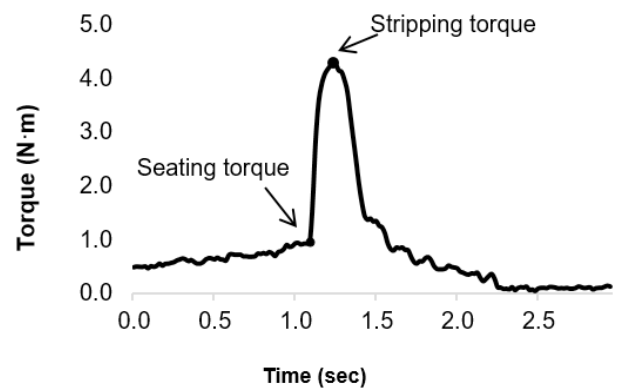

FIGURE 2 Typical torque-time curve when driving screws into face of MDF

\section{Mean Screw-driving Torque Comparisons}

Table 3 summarizes the mean SET and STT values for driving screws into the MDF specimens. In general, the mean SET values were significantly lower than the mean STT values. The mean SET values ranged from 0.37 to $1.23 \mathrm{~N} \cdot \mathrm{m}$ for side specimens and from 0.57 to 1.56 $\mathrm{N} \cdot \mathrm{m}$ for the face specimens while the STT values ranged from 1.18 to $2.68 \mathrm{~N} \cdot \mathrm{m}$ for the side specimens and from 2.89 to $5.4 \mathrm{I} \mathrm{N} \cdot \mathrm{m}$ for the face specimens. Table 3 also lists the STT to SET ratios, which ranged between 2.I and 4.3 for the side specimens and between 3.2 and 5.1 for the face specimens. The results of this study indicated that the STT to SET ratio of 3.2 for driving screws into the face of MDF with no pilot hole drilled was higher than that of 1.3 for driving screws into WPCs (Kuang, 20I6), but lower than those of 3.5 and 3.3 for driving screws into OSB and PB (Tor et al., 2016). For the side specimens, the ratio of 3.2 for MDF with no pilot holes was higher than those of I.3, 3.2, and 3.I for WPC, OSB, and PB (Tor et al, 20I5; Yu et al, 2015 and Kuang, 20I7) . If the STT to SET ratio of any material was lower than 3 , greater skills were required for operators to drive screws using power tools (Robert, 20I5).

ANOVA and mean comparison analyses of the screw-driving torques were performed on the SET and STT data, separately. The interaction between the embedded screw orientation and pilot hole diameter was statistically significant for both data sets. A one-way classification for 12 combinations of embedded screw
TABLE 3Mean SET and STT values for MDF specimen.

\begin{tabular}{|c|c|c|c|c|}
\hline \multirow{2}{*}{$\begin{array}{c}\text { Embedded screw } \\
\text { orientation }\end{array}$} & \multirow{2}{*}{$\begin{array}{l}\text { Pilot-hole } \\
\text { diameter } \\
(\mathrm{mm})\end{array}$} & \multicolumn{2}{|c|}{$\begin{array}{l}\text { Screw-driving torques } \\
(\mathrm{N} \cdot \mathrm{m})\end{array}$} & \multirow{2}{*}{$\begin{array}{l}\text { STT/SET } \\
\text { ratio }\end{array}$} \\
\hline & & SET & STT & \\
\hline \multirow{6}{*}{ Side } & 0 & $0.37(13) *$ & $1.18(14)$ & 3.2 \\
\hline & 2.8 & $1.06(10)$ & $2.24(6)$ & 2.1 \\
\hline & 3.2 & $1.23(12)$ & $2.68(6)$ & 2.2 \\
\hline & 3.6 & $0.75(\mathrm{II})$ & $2.47(13)$ & 3.3 \\
\hline & 4.0 & $0.51(\mathrm{II})$ & $1.97(\mathrm{II})$ & 3.9 \\
\hline & 4.4 & $0.40(14)$ & $1.73(6)$ & 4.3 \\
\hline \multirow{6}{*}{ Face } & 0 & $1.38(13)$ & $4.42(8)$ & 3.2 \\
\hline & 2.8 & $\mathrm{I} .49(\mathrm{II})$ & $5.13(5)$ & 3.4 \\
\hline & 3.2 & $1.56(9)$ & $5.4 \mathrm{I}(8)$ & 3.5 \\
\hline & 3.6 & I.0I (I3) & $4.02(9)$ & 4.0 \\
\hline & 4.0 & $0.80(\mathrm{II})$ & $3.55(8)$ & 4.4 \\
\hline & 4.4 & $0.57(14)$ & $2.89(8)$ & 5.1 \\
\hline
\end{tabular}

* Values in parentheses are coefficient of variation (\%).

orientation and pilot hole diameter was created for SET and STT, respectively, to evaluate the mean differences between the different combinations (Tables 4). The protected LSD values were 0.073 and $0.170 \mathrm{~N} \cdot \mathrm{m}$ for SET and STT, respectively.

Effect of pilot hole diameter

Table 4 showed the statistically significant results in the mean SET and STT values among the pilot hole diameters, regardless of the embedded screw orientations. An increasing trend can be observed in the SET for driving screws into the side of MDF when the pilot hole diameter increased from 0 to $3.2 \mathrm{~mm}$ while there was a decreasing trend when the pilot hole diameter increased from 3.2 to $4.4 \mathrm{~mm}$. Tor (20II) found that the SET values for side MDF specimens were $0.38,0.4 \mathrm{I}$, and $0.46 \mathrm{~N} \cdot \mathrm{m}$ when the pilot hole diameters of I.6, 2.0, and $2.4 \mathrm{~mm}$ drilled whereas the STT values were I.36, I.49, and I.64 N.m with the corresponding pilot hole diameters, respectively.

A pilot hole diameter of $3.2 \mathrm{~mm}$ which was $68 \%$ of the major diameter and $93 \%$ of the minor diameter of

TABLE 4 Mean SET and STT values for pilot hole diameter for each embedded screw orientation.

\begin{tabular}{|c|c|c|c|c|c|c|c|}
\hline \multirow{2}{*}{$\begin{array}{l}\text { Screw- } \\
\text { driving } \\
\text { torques }\end{array}$} & \multirow{2}{*}{$\begin{array}{l}\text { Embedded } \\
\text { screw } \\
\text { orientation }\end{array}$} & \multicolumn{6}{|c|}{ Pilot hole diameter $(\mathrm{mm})$} \\
\hline & & 0 & 2.8 & 3.2 & 3.6 & 4.0 & 4.4 \\
\hline & & ------- & 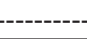 & ------( & m)-----. & -----.. & ------- \\
\hline \multirow{3}{*}{ SET } & Side & $(0.37)$ & $(1.06)$ & $(1.23)$ & $(0.75)$ & $(0.5 \mathrm{I})$ & $(0.39)$ \\
\hline & & $\frac{E^{*}}{20}$ & B & A & $\mathrm{C}$ & D & \\
\hline & Face & $\begin{array}{c}\text { (1.38) } \\
B\end{array}$ & $\begin{array}{c}(1.49) \\
\text { A }\end{array}$ & $\begin{array}{c}(1.56) \\
\text { A }\end{array}$ & $\begin{array}{c}(1.01) \\
C\end{array}$ & $\begin{array}{c}(0.80) \\
D\end{array}$ & $\begin{array}{c}(0.57) \\
E\end{array}$ \\
\hline \multirow{4}{*}{ STT } & Side & $(1.18)$ & $(2.24)$ & $(2.69)$ & $(2.47)$ & $(1.98)$ & $\begin{array}{l}(1.73) \\
\end{array}$ \\
\hline & & $\mathrm{F}$ & C & A & B & D & $\mathrm{E}$ \\
\hline & Fas & $(4.42)$ & $(5.13)$ & $(5.4 I)$ & $(4.02)$ & (3.55) & $(2.89)$ \\
\hline & & C & B & A & D & $\mathrm{E}$ & $\mathrm{F}$ \\
\hline
\end{tabular}

*Means not followed by a common letter are significantly different from one another at the $5 \%$ significance level. 
the screw, had the highest mean SET values for the side and face specimens of MDF. The lowest mean SET value was obtained when the side specimen drilled by the pilot hole diameter of $4.4 \mathrm{~mm}$ and no pilot hole diameter used. The MDF side specimens with no diameter drilled had some splitting problems because the screw torn the fiber apart in order to give some room for the screw which caused directly low screw-driving performance. In the other situation using a drill bit of $4.4 \mathrm{~mm}$, when the screw was driven into side of MDF, there was almost no fibers to hold on to the inside of the pilot hole which also decrease the screw-driving torque performance. The highest mean SET value was obtained with a pilot hole diameter of $3.2 \mathrm{~mm}$ when driving screws into the face of the MDF, but there was no significant difference with a pilot hole diameter of $2.8 \mathrm{~mm}$.

\section{Effect of embedded screw orientation}

A pilot hole diameter of $3.2 \mathrm{~mm}$ had significantly higher mean STT value for both embedded screw orientations. The mean STT values decreased by $\% 64$ and $\% 53$ for side and face orientations, respectively when the pilot hole diameter increased from 3.2 to $4.4 \mathrm{~mm}$.

\section{Prediction Equation}

To quantify the effects of pilot hole diameter and embedded screw orientation and obtain functional relationships between the SET and STT, the least squares regression technique of using the following power equation [2] was proposed to fit to the individual test data points. Where $T$ is screw-driving torque $(\mathrm{N} \cdot \mathrm{m})$; $\alpha$ is pilot hole diameter $(\mathrm{mm}) ; \beta$ is embedded screw orientation; a,b,c are regression fitting constants.

$\mathrm{T}=\mathrm{a} \alpha^{b} \times \beta^{c}$

In addition, a linear equation was also investigated to fit to test data, but its $r$ square value was lower than the one of power equation. The regression analysis yielded the following significant power equations [3] and [4] with its coefficient of determination, $r^{2}$ of 0.25 and 0.68 for SET and STT and p-values of all less than 0.000 I for both data sets:

$$
\begin{aligned}
& \mathrm{SET}=-0.160 \alpha^{0.726} \times \beta^{-0.073} \\
& \mathrm{STT}=0.244 \alpha^{1.071} \times \beta^{0.108}
\end{aligned}
$$

The mean SET and STT values could be predicted in MDF based on [3] and [4] as a function of factors of pilot-hole diameter and embedded screw orientation. The regression model proposed in this study could be a useful technique for deriving the relationship between screw-driving torques and their significant factors.

\section{CONCLUSIONS}

In this study, screw-driving torques in MDF were investigated by evaluating the effects of different factors, such as the pilot hole diameter and embedded screw orientation. In general, the mean SET and STT values for MDF drilled with a pilot hole having a diameter of $3.2 \mathrm{~mm}$ were higher than the corresponding values for other diameters, regardless of the embedded screw orientations. The driving of the screws into the side of the MDF material might cause some splitting problems without having pilot holes. To prevent this splitting problem and attain better screw performance, the pilot hole diameter must be selected carefully. Therefore, this study indicates that it is better to use a drill bit of 3.2 mm which is the $68 \%$ of major diameter and $93 \%$ minor of diameter in order to increase the screw performance based on the screw-driving torques. The drill bit of 2.8 $\mathrm{mm}$ which is $60 \%$ major of diameter and $81 \%$ of minor diameter can also be used as a second choice. Based on this, diameters of 2.8 and $3.2 \mathrm{~mm}$, i.e., $81 \%$ and $93 \%$ of the major diameter of the screw, produces better SET and STT results than any other pilot hole diameters in MDF. Since the pilot hole diameter is critically important for the MDF manufacturers and consumers, a study needs to be carried out on the direct screw withdrawal resistance at different level of screw-driving torques between SET and STT in MDF. A power equation was derived for the estimation of SET and STT constants using significant parameters, but it is limited to MDF material used in this study. Further validation is required if these derived equations are used for general applications in other materials.

\section{ACKNOWLEDGEMENT}

The author would like to thank to the Department of Sustainable Bioproducts at Mississippi State University for providing experimental facilities.

\section{REFERENCES}

ASTM D 1037-06. Standard test methods for evaluating properties of wood-base fiber and particle panel materials. American Society for Testing and Materials, West Conshohocken, PA, 2010.

ASTM D 4442-92. Standard test methods for direct moisture content measurement of wood and wood-base materials. American Society for Testing and Materials, West Conshohocken, PA, 2010.

BOULANGER, K.A. Statistical and experimental analysis of a torque model for self-tapping screws. A major qualifying project report. Worcester Polytechnic Institute, 2009. 
CAI, Z. Selected properties of MDF and flakeboard overlaid with fiberglass mats. Forest Products Journal, v. 56, n.I I/I2, p. I42-I46, 2006.

ITHNIN, Z.; RAJAK, H.A.; ECKELMAN, C.A. Edge and face withdrawal strength of large screws in particleboard and medium density fiberboard. Journal of Forest Products, v. 43, p. $25-30,1993$.

KUANG, F.; XING, Y.; WU, Z.; ZHANG, J. Characteristics of screwdriving torques in wood-plastic composites. Wood and Fiber Science, v.49, n.2, p. 206-218, 2017.

ROBERT, A.M. Plastic part design for injection molding: An introduction. Hanser Publications, 2012. 568p. Verificar ano texto consta 2015.
TOR, O. Effects of driving torques on screw withdrawal resistance from wood-based composites. 20II. 174p. Master thesis Mississippi State University, USA, 201 I .

TOR, O.; YU, X.; ZHANG, J. Characteristics of torques for driving screws into wood-based composites. Wood Fiber Science, v. 47, n. I, 20I5. Conferir se é science mesmo

TOR, O.; DEMIREL, S.; HU, L.; ZHANG, Z. Effects of driving screws on direct screw withdrawal resistance in OSB. Kastamonu University Journal of Forestry Faculty, v. 16, n. 2, p.438-446, 2016.

YU, X.; TOR, O.; QUIN, F; SEALE, D.; ZHANG, J. Screwdriving torques in particleboards. Wood and Fiber Science, v. 47, n. 2, 2015. 